\title{
Experimental and calculated evaluation of carbon fiber reinforcing for increasing concrete columns carrying capacity
}

\author{
Ekaterina Kuzina*, and Vladimir Rimshin
}

Moscow State University of Civil Engineering, Yaroslavskoe shosse, 26, Moscow, 129337, Russia

\begin{abstract}
The article presents the concrete columns tests results reinforced with canvases based on carbon fibers FibARM Tape 530/300 and FibARM Lamel 14/100 slats, the calculation of the use effectiveness for strengthening the compressed reinforced concrete elements. Three groups of columns were tested: unreinforced columns, columns reinforced with FibARM Tape 530/300 canvases in one layer, reinforced with FibARM Lamel 14/100 lamella (width is $100 \mathrm{~mm}$ ), while one of the samples was reinforced with lamella only, and the other was reinforced both lamella and clamps. In addition, it was proposed calibration calculation of concrete columns reinforced with canvases based on carbon fibers FibARM Tape 530/300, the calculation purpose was to determine the bearing capacity for evaluating the suitability in the further structure operation after columns strengthening. According to the experiment results, data were obtained on the carrying capacity of centrally compressed concrete columns reinforced with carbon fiber both with a discrete arrangement of bands (strips) made of composite material along the height of the structures, as well as with their continuous wrapping (analogue of reinforced concrete holder). According to the experiment results, data were obtained on the carrying capacity of centrally compressed concrete columns reinforced with carbon fiber, both with a discrete arrangement of bands (strips) made of composite material along the height of structures, and with their continuous wrapping (analogue of reinforced concrete holder).
\end{abstract}

\section{Introduction}

Bearing columns are used as the main element for the perception of compressive loads in buildings. The reliability of the whole structure is preserved due to these elements. But often the calculated indicators of the columns are not suitable for the tasks that they have to perform in practice. Then the columns require reinforcement $[1,2]$.

There are many reasons why there is a need for increasing the reliability of such elements. In most cases, the necessity for strengthening the columns arises if visible defects appear on them. In addition to ordinary cracks, the formation of a slope or roll should also

\footnotetext{
* Corresponding author: kkuzzina@ mail.ru
} 
be attributed to serious deformations. Another case for resorting to the strengthening of columns is the area building expansion. Load increasing on these elements may not be foreseen by the original project. Any major overhaul or reconstruction can lead to a reduction in the carrying capacity of columns. Then it is impossible to exploit the building without amplification [3-4,6-8].

Strengthening with composite materials in the form of carbon tapes and canvases is gluing the latter on a specially prepared surface of reinforced concrete structures, which gives them the necessary strength with virtually no weight gain. The fundamental characteristic of carbon fiber is its elastic deformation up to fracture. This material does not have plastic properties, its destruction is brittle, and this property allows not to redistribute stresses and not to change the calculated overlap scheme after its strengthening. The experience of Russian and foreign scientists and practitioners proves that concrete structures reinforcement using modern composite materials is more economical than traditional methods. The technology is simple and does not require the use of heavy equipment and temporary supports $[5,9]$.

\section{Experiments and methods}

Experimental studies of the reinforced concrete elements carrying capacity using composite materials were launched abroad. The tests were subjected to concrete structures, reinforced with composite materials based on glass, aramid, carbon and other fibers. Subsequently, the efficiency of structures reinforcement with composite materials based on carbon fibers was revealed [10-12].

The paper presents the results of tests of reinforced concrete columns when reinforced with canvases based on carbon fibers FibARM Tape 530/300 and lamels FibARM Lamel $14 / 100$, and also proposed the calculation of concrete columns reinforced with canvases based on carbon fibers FibARM Tape 530/300 [7]. The height of the columns is $2500 \mathrm{~mm}$, the cross-section is square with a side of $400 \mathrm{~mm}$. Concrete class for strength is not less than B20, frost resistance is F300 and waterproof is W6. The column reinforcement scheme is shown in Figure 1.
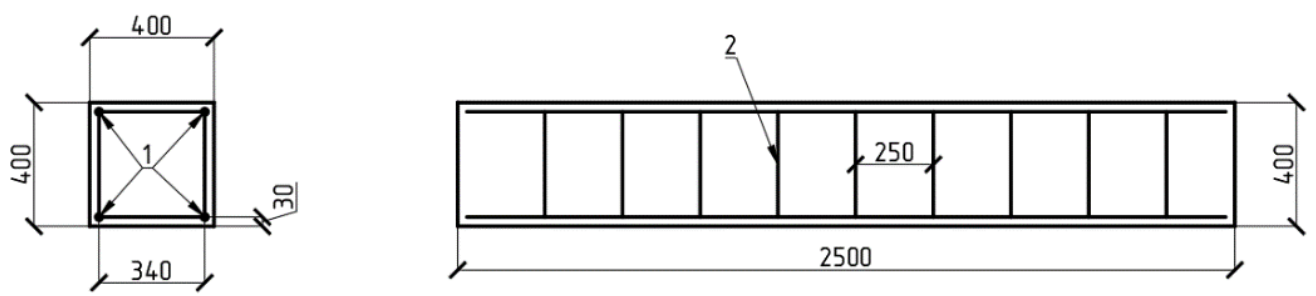

Fig. 1. The design and scheme of concrete columns reinforcement: 1 - bar reinforcement with a diameter of $10 \mathrm{~mm}$, class A400, 2 - transverse reinforcement with a diameter of $6.5 \mathrm{~mm}$, class A240

Three groups of columns were tested: A - unreinforced columns, B - columns reinforced with FibARM Tape 530/300 clamps in one layer (Figure 2), C - reinforced with $100 \mathrm{~mm}$ wide FibARM Lamel 14/100 lamella, while sample 5 was reinforced only with lamella (Figure 3) and the sample 6 was reinforced both with lamella and clamps (Figure 4). 


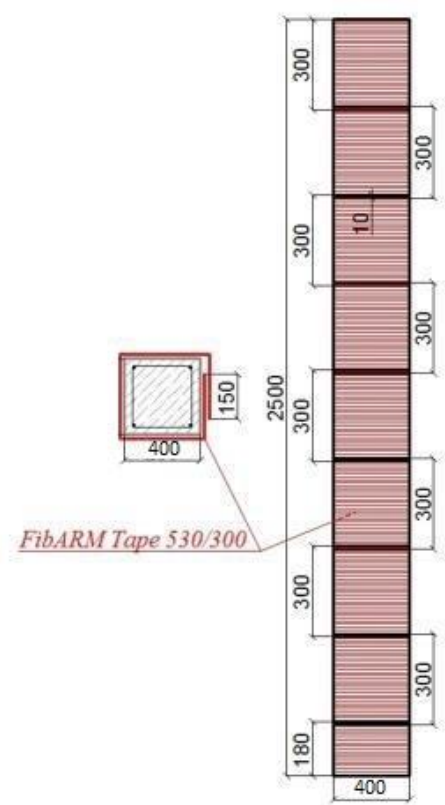

Fig. 2. Columns strengthening scheme (group B)

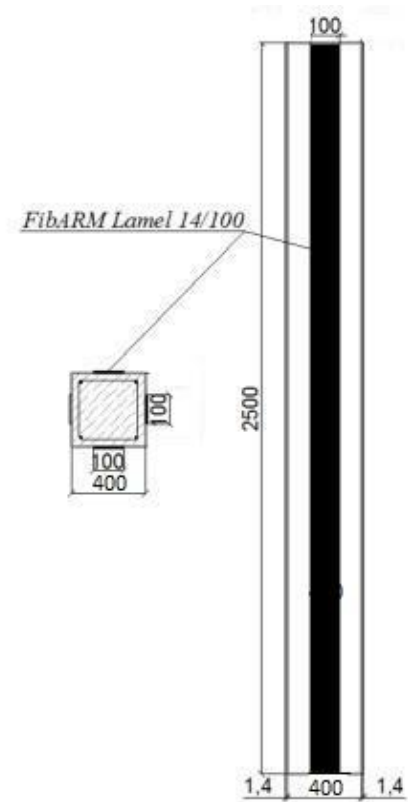

Fig. 3. Columns strengthening scheme (group C) by lamella only

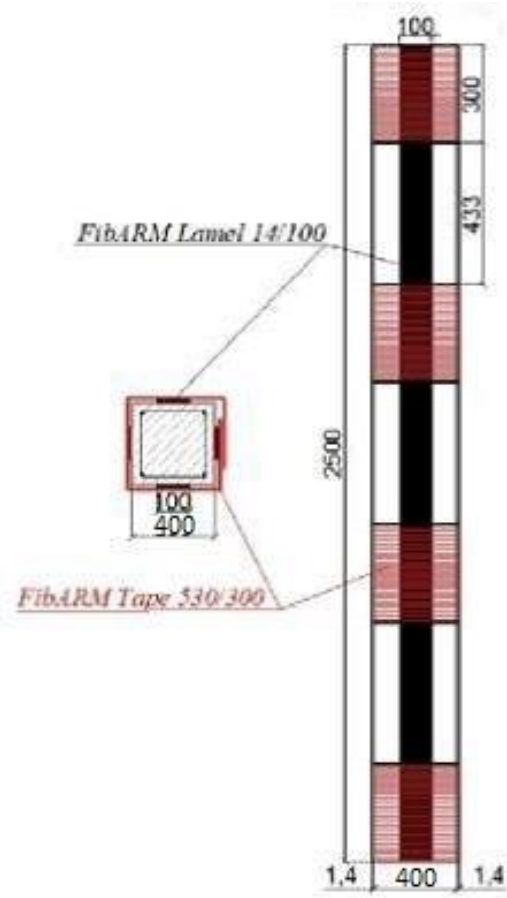

Fig. 4. Columns strengthening diagram (group C) both lamellas and canvases

The load was applied to the column in steps of 5,000 kg at a speed of $500 \mathrm{~kg} / \mathrm{min}$ [7]. The tests were carried out at a temperature of $+(15-22)^{\circ} \mathrm{C}$ on a CD 20/400 PU testing machine according to the axial compression scheme, while absolute deformations were recorded at the base of $500 \mathrm{~mm}$ in the middle of the column length. The load was applied to 
the column in steps of $5,000 \mathrm{~kg}$ at a speed of $500 \mathrm{~kg} / \mathrm{min}$ [7].

Figure 5 shows the process of testing an unreinforced column (left) and reinforced with canvases (right).

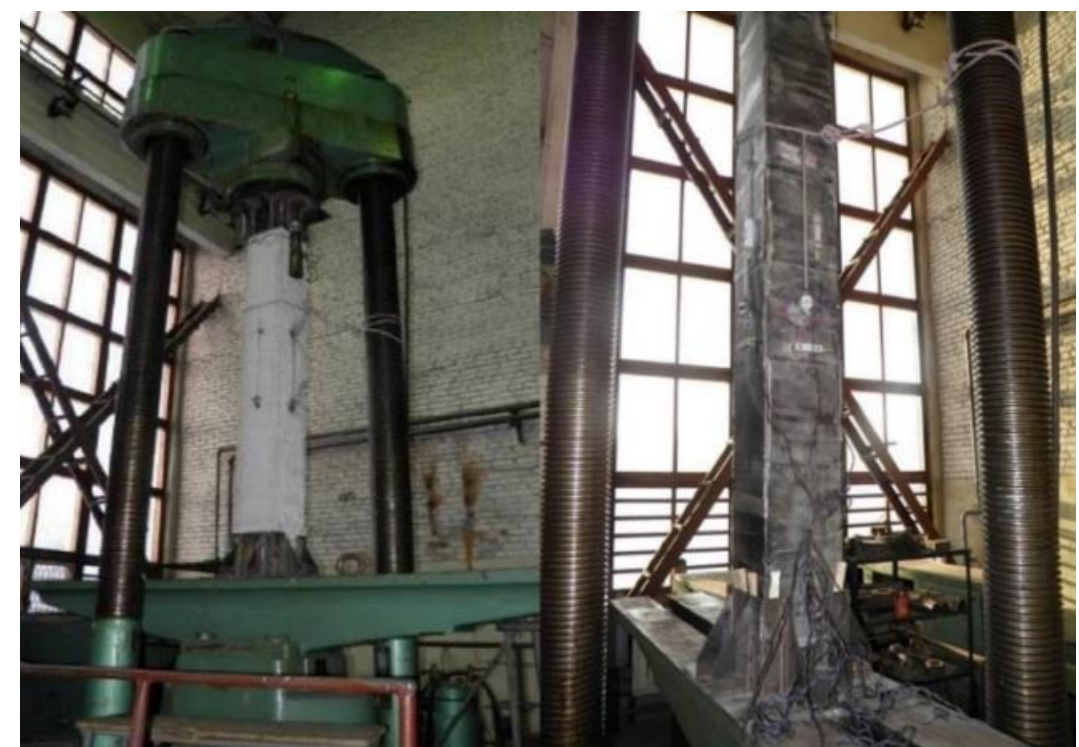

Fig. 5. The test process of unreinforced (left) and reinforced with canvases (right) concrete columns

Figure 6 shows the testing process for concrete columns reinforced with lamella (the left figure) and both lamella and canvases (the right figure).

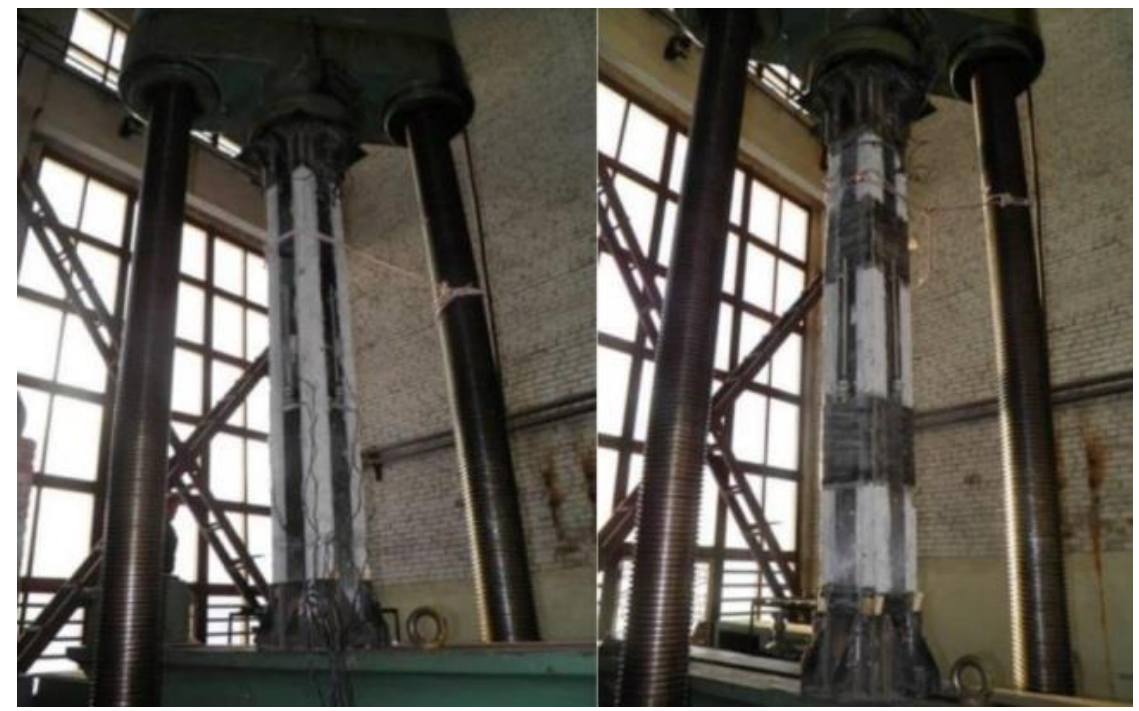

Fig. 6. The process of testing concrete columns reinforced with lamella (left) and lamellae and reinforced with holders (right)

Table 1 shows the values of destructive loads for different groups of columns, obtained as a result of tests. 
Table 1. The test results of reinforced concrete columns with different amplification schemes

\begin{tabular}{|c|c|c|c|c|c|}
\hline \multirow{2}{*}{ Group } & $\begin{array}{c}\text { Column } \\
\text { number }\end{array}$ & $\begin{array}{c}\text { Destructive } \\
\text { load, } \mathbf{k N}\end{array}$ & $\begin{array}{c}\text { Compressive } \\
\text { strength, MPa }\end{array}$ & $\begin{array}{c}\text { The increase } \\
\text { Average } \\
\text { in bearing } \\
\text { strength, MPa } \\
\text { capacity of the } \\
\text { column in } \\
\text { compression, } \\
\%\end{array}$ \\
\hline \multirow{2}{*}{ A } & 1 & 1274 & 20 & 18,5 & 0 \\
\cline { 2 - 6 } B & 2 & 1078 & 17 & 28,5 & 54 \\
\cline { 2 - 6 } C & 4 & 1666 & 27 & 20 & 8 \\
\cline { 2 - 6 } & 5 & 1862 & 20 & 25 & 35 \\
\hline
\end{tabular}

According to test results, it was established that reinforcement of concrete columns working in compression by winding them with carbon canvases led to an increase in bearing capacity for compression by $54 \%$, while strengthening them with lamella increased the bearing capacity of columns only by $8 \%$, and only the addition of partial winding to the lamella with canvases led to an increase in the compressive capacity by $35 \%$.

\section{Calculations and results}

The article proposed a calibration calculation of concrete columns reinforcement with canvases based on carbon fibers FibARM Tape 530/300, the purpose of which was determining the bearing capacity for evaluating the suitability in the further operation of the structure after the work on columns reinforcement. The purpose of the verification calculations is determining the bearing capacity to assess the suitability in the further operation of the structure after the work on the column's reinforcement.

Design class of columns concrete is B35. There are columns with a conditional class of concrete B20. Strengthening of the columns which have not gained durability to a design class is required.

The composite material based on carbon fibers FibARM Tape 530/300 is taken for strengthening columns, which has the following characteristics, presented in Table 2.

Table 2. Characteristics of FibARM Tape 530/300

\begin{tabular}{|c|c|c|c|c|}
\hline $\begin{array}{c}\text { Type of } \\
\text { composite } \\
\text { material }\end{array}$ & $\begin{array}{c}\text { Thickness, } \\
\text { mm }\end{array}$ & $\begin{array}{c}\text { Tensile strength, } \\
\text { MPa }\end{array}$ & $\begin{array}{c}\text { The modulus of } \\
\text { tensile elasticity, } \\
\text { MPa }\end{array}$ & $\begin{array}{c}\text { Tape width } \\
\text { mm }\end{array}$ \\
\hline $\begin{array}{c}\text { FibARM Tape } \\
530 / 300\end{array}$ & 0,166 & 4900 & 230000 & 300 \\
\hline
\end{tabular}

The calculation of the concrete columns reinforced with a conditional class of concrete B20:

Actual characteristics:

$\mathrm{R}_{\mathrm{b}}=11,5(\mathrm{MPa})[\mathrm{B} 20]$

$\mathrm{h}=400(\mathrm{~mm})$

$\mathrm{b}=400(\mathrm{~mm})$.

The distance between the transverse canvases in the light is $\mathrm{S}=50 \mathrm{~mm}$. The sticker transverse canvases were accepted in two layers [11]. 
Estimated carbon tensile strength:

$$
R_{f}=R_{f, n} \cdot \frac{\gamma_{1} \cdot \gamma_{2} \cdot \gamma_{3}}{\gamma_{4}}=4900 \cdot \frac{0,9 \cdot 0,8 \cdot 0,772}{1,1}=2476,0 \mathrm{MPa}
$$

$\gamma_{1}-$ is the coefficient of working conditions ( 0.9 is for indoor use);

$\gamma_{2}-$ is the coefficient of working conditions for various materials $(0.8$ is for carbon fiber fabric);

$\gamma_{3}$ - coefficient taking into account the adhesion of the composite material with concrete, is calculated by the formula 3 .

Checking condition for exfoliation:

$$
n \cdot E_{f t} \cdot t_{f}=2 \cdot 230000 \cdot 0,166=76360 \leq 180000
$$

this implies:

$$
\gamma_{3}=\frac{1}{60 \cdot \varepsilon_{f}} \cdot\left(1-\frac{n \cdot E_{f} \cdot t_{f}}{360000}\right)=\frac{1}{60 \cdot 0,017} \cdot\left(1-\frac{76360}{360000}\right)=0,722 \leq 0,9
$$

Since $\gamma_{3}$ does not exceed 0,9 , it is taken that $\gamma_{3}=0,772$.

$\gamma_{4}-$ the reliability coefficient ( 1.1 is for calculating structures according to the limiting states of the first group);

Estimated value of tensile strain:

$$
\varepsilon_{f}=\varepsilon_{f n} \cdot \frac{C_{E}}{\gamma^{4}}=\frac{0,021 \cdot 0,9}{1,1}=0,017
$$

$\mathrm{C}_{\mathrm{E}}$ - the working conditions coefficient, it is taken 0.9.

Relative deformations limit value of carbon canvas elongation:

$$
\varepsilon_{f n}=\varepsilon_{f} \cdot \gamma_{3}=0,017 \cdot 0,9=0,0153
$$

The calculated values of the tensile modulus:

$$
\mathrm{E}_{\mathrm{fn}}=\mathrm{E}_{\mathrm{f}}=230000 \mathrm{MPa}
$$

The bearing capacity of the reinforced column is checked by the formula:

$$
\begin{gathered}
\left.\mathrm{R}_{\mathrm{b} .1}=R_{b}\left(2,254 \cdot\left(\sqrt{\left(1+\left(558,18 \cdot \frac{R_{l}}{R_{b}}\right.\right.}\right)\right)-140,6 \cdot \frac{R_{l}}{R_{b}}-1,254\right)=22,30 \mathrm{MPa} \\
\mathrm{R}_{\mathrm{l}}=0,0038 \cdot \mathrm{K}_{1} \cdot \mathrm{R}_{\mathrm{f}}=0,0038 \cdot 0,00332 \cdot 2476,0=0,0312 \\
\mathrm{~K}_{1}=2 \cdot \mathrm{t}_{\mathrm{f}} \cdot \frac{b+h}{b \cdot h}=0,00332
\end{gathered}
$$

The following condition must be met for designing:

$$
\begin{gathered}
E_{f} \cdot \varepsilon_{f u} \leq 0,75 \cdot \mathrm{R}_{\mathrm{f}, \mathrm{n}} \\
230000 \cdot 0,0153=3519<0,75 \cdot 4900=3675 \quad \text { (condition is met). }
\end{gathered}
$$

Design concrete resistance of reinforced construction to compression:

$$
\begin{gathered}
\beta=\left(1-\frac{s}{b+h}\right)^{2}=\left(1-\frac{50}{50+50}\right)^{2}=0,879 \\
\mathrm{R}_{\mathrm{b}, \text { hoop }}=\left(\mathrm{R}_{\mathrm{b} 1}-\mathrm{R}_{\mathrm{b}}\right) \cdot \beta+\mathrm{R}_{\mathrm{b}}=(22,30-11,5) \cdot 0,879+11,5=20,99 \mathrm{MPa}
\end{gathered}
$$




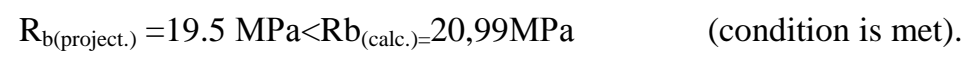

\section{Conclusions}

According to the experiment results, data were obtained on the carrying capacity of centrally compressed concrete columns reinforced with carbon fiber, both with a discrete arrangement of bands (strips) made of composite material along the height of structures, and with their continuous wrapping (analogue of reinforced concrete holder) [13-14]. Test results analysis shows that reinforcement of concrete columns working in compression by winding them with carbon canvases led to an increase in bearing capacity for compression by $54 \%$, while strengthening them with lamella increased the bearing capacity of columns only by $8 \%$, and only the partial winding addition to lamella with canvases led to an increase in the compressive capacity by $35 \%$.

\section{References}

1. Antoshkin V.D., Travush V.I., Erofeev V.T., Rimshin V.I., Kurbatov, V.L., The problem optimization triangular geometric line field, (Modern Applied Science 9(3), 2015)

2. Krishan A., Rimshin V., Erofeev V., Kurbatov V., Markov S., The energy integrity resistance to the destruction of the long-term strength concrete, (Procedia Engineering, 117(1), 2015)

3. Erofeev V.T., Bogatov A.D., Smirnov V.F., Rimshin V.I., Kurbatov V.L., Bioresistant building composites on the basis of glass wastes, (Biosciences Biotechnology Research Asia, 12(1), 2015)

4. Bazhenov Y.M., Erofeev V.T., Rimshin V.I., Markov S.V., Kurbatov V.L., Changes in the topology of a concrete porous space in interactions with the external medium, (Engineering Solid Mechanics, 4(4), 2016)

5. Cherkas A., Rimshin V., Application of composite reinforcement for modernization of buildings and structures. (MATEC Web of Conferences 117,00027. 2017)

6. Erofeev V.T., Zavalishin E.V., Rimshin V.I., Kurbatov V.L., Stepanovich M.B., Frame composites based on soluble glass, (Research Journal of Pharmaceutical, Biological and Chemical Sciences, 7(3), 2016)

7. Erofeev V., Kalashnikov V., Karpushin S., Tretiakov I., Matvievskiy A., Physical and mechanical properties of the cement stone based on biocidal Portland cement with active mineral additive. Solid State Phenomena, 871, 2016)

8. Korotaev S.A., Kalashnikov V.I., Rimshin V.I., Erofeeva I.V., Kurbatov V.L., The impact of mineral Aggregates on the thermal conductivity of cement composites, (Ecology, Environment and Conservation, 22(3), 2016)

9. Krishan A.L., Rimshin V.I., Telichenko V.I., Rakhmanov V.A., Narkevich M.Yu., Practical implementation of the calculation of the bearing capacity trumpet-concrete column, (Izvestiya Vysshikh Uchebnykh Zavedenii, 2017)

10. Krishan A.L., Troshkina E.A., Rimshin V.I., Rahmanov V.A., Kurbatov V.L., Loadbearing capacity of short concrete-filled steel tube columns of circular cross section, (Research Journal of Pharmaceutical, Biological and Chemical Sciences, 7(3), 2016)

11. Shubin I.L., Zaitsev Y.V., Rimshin V.I., Kurbatov V.L., Sultygova P.S., Fracture of high performance materials under multiaxial compression and thermal effect, (Engineering Solid Mechanics, 5(2), 2017) 
12. Telichenko V.I., Rimshin V.I., Karelskii A.V., Labudin B.V., Kurbatov V.L. Strengthening technology of timber trusses by patch plates with toothed-plate connectors, (Journal of Industrial Pollution Control, 2017)

13. Telichenko V., Rimshin V., Eremeev V., Kurbatov V., Mathematical modeling of groundwaters pressure distribution in the underground structures by cylindrical form zone. (MATEC Web of Conferences 27. Cep. "27th R-S-P Seminar, Theoretical Foundation of Civil Engineering (27RSP), TFoCE 2018", 2018)

14. Varlamov A.A., Rimshin V.I., Tverskoi S.Y., Planning and management of urban environment using the models of degradation theory, (IOP Conference Series: Earth and Environmental Science 3. Cep. "International Conference on Sustainable Cities", 2018) 